\title{
Parametric Optimization of Abrasive Water Jet Machining of Inconel 800H Using Taguchi Methodology
}

\author{
D. Sidda Reddy ${ }^{1, *}$, A. Seshu Kumar ${ }^{2}$, M.Sreenivasa Rao ${ }^{1}$ \\ ${ }^{1}$ Department of Mechanical Engineering, JNTUH college of Engineering, Hyderabad \\ ${ }^{2}$ Senior Principal Scientist and Head, Engineering Services Division, Indian Institute of Chemical Technology, Hyderabad \\ *Corresponding Author: siddareddy2009@gmail.com
}

Copyright (C) 2014 Horizon Research Publishing All rights reserved.

\begin{abstract}
Inconel $800 \mathrm{H}$ has got wide applications due to its resistance to high temperature, corrosion. Because of its poor machinability to process it, among nontraditional processes abrasive water jet machining is commonly used. Abrasive Water Jet Machining (AWJM) of Inconel $800 \mathrm{H}$ has commercial significance due to its good machining characteristics. In the present paper an attempt has been made to optimise machining parameters employed in Abrasive Jet Machining of Inconel $800 \mathrm{H}$ using Taguchi method. The approach used is based on the analysis of variance and signal to noise ratio (SN Ratio) to optimize the AWJM process parameters for effective Material Removal Rate (MRR) and Surface Roughness (SR). Important AWJM machining parameters such as water pressure, focussing tube size, traverse speed $\&$ abrasive flow rate were predicted for optimised MRR and SR. It was confirmed that determined optimal combination of AWJM process parameters satisfy the real need for machining of Inconel $800 \mathrm{H}$ in actual practice.
\end{abstract}

Keywords Abrasive Water Jet Machine (AWJM), Taguchi method, ANOVA,SN Ratio, MRR, SR

\section{Introduction}

Among nickel based alloys nickel-iron-chromium alloy namely Inconel 800H(UNS N0081) has good mechanical properties like high corrosion resistance and can withstand high temperatures up to $620^{\circ} \mathrm{C}$. It has good ability to resist oxidation and carburization.It is used in chemical and power plants for re - heater tubing, steam generators, steam methane reformer pigtails, sheathing for electrical heating elements, headers, furnace tubing and also in many food processing equipment. As the alloy has high strength it cannot be machined by using the traditional methods because of its work hardening nature. Hence non-traditional methods like abrasive water jet machining and laser machining etc. are used. Laser Cutting is generally economical for cutting Inconel $800 \mathrm{H}$ sheets up to $3 \mathrm{~mm}$ thick and beyond $3 \mathrm{~mm}$ thick abrasive water jet machining is often used. On the other hand, AJWM is preferred over laser cutting because of its capacity to machine the components with least slot width.

Abrasive water jet machining of aluminum, grey cast iron, mild steel and composites and hard polymers has been studies extensively [1-6] for optimized material removal rate (MRR) and surface roughness (SR) using Taguchi method. Nozzle traverse speed and water pressure are significant influencing factors in case of MRR while abrasive flow rate and water pressure strongly influences SR [1-5]. Other parameters such as standoff distance, abrasive grit size are sub-significant in influencing MRR or SR. It was noted [6] that ferrous materials require significantly high abrasive mass flow rate compared to non-ferrous materials while metal matrix composites and hard polymers can be machined using moderate abrasive flow rates. Although abrasive jet water machining of Inconel was prevalent optimization of machining parameters did not receive much attention. Hence in the present work an attempt has been made to optimize the cutting parameters in the AWJM of Inconel $800 \mathrm{H}$ alloy using Taguchi method. Nozzle transverse speed, abrasive flow rate and standoff distance were optimized for material removable rate (MRR) and surface roughness ( SR ). Analysis of variance ( ANOVA, F-Tests and Signal to Noise ratio were used for optimization of machining parameters.

\section{Materials and Methods}

An Inconel alloy $800 \mathrm{H}$ in $6 \mathrm{~mm}$ sheet thickness with following composition was studied in the present investigation. Nickel $30.0 \%$ \%-35.0 \% ; Chromium $19.0 \%-23.0 \%$; Iron $39.5 \%$ min; Carbon $0.05 \%-0.10 \%$; Aluminum $0.15 \%-0.60 \%$; Titanium $0.15 \%$-0.60 \%; Aluminum + Titanium $0.30 \%-1.20 \%$; ASTM grain size 5 or coarser; UNS designation N08810.

The abrasive water jet machining equipment used consists 
of a high pressure pump Streamline SL-V 50 Plus made by KMT that is fitted on a CNC cutting portal with an abrasive feeding system that varies the feed rate in the range of $100-$ 10000 grams $/ \mathrm{min}$. Abrasive material used was Garnet sand. The water nozzle (orifice) used had an inner diameter of 0.35 $\mathrm{mm}$ and the focusing tube (nozzle) innerdiameter was $1.10 \mathrm{~mm}$. Abrasive material $80 \mathrm{mesh}$ was chosen (the values of abrasive particles granulation varies between $150-300 \mu \mathrm{m}$ ) with a density of $2300 \mathrm{~kg} / \mathrm{m}^{3}$.

Table 1. Machining Parameters with Level value

\begin{tabular}{|c|c|c|c|}
\hline Machining Parameter & Level 1 & level 2 & Level 3 \\
\hline Transverse speed (mm /min) & 160 & 200 & 225 \\
\hline Abrasive flow rate ( grams / min) & 500 & 600 & 700 \\
\hline Standoff distance (mm) & 2 & 3 & 4 \\
\hline
\end{tabular}

Taguchi's experimental design was used to construct the design of experiments (DOE). In this paper we have selected machining process parameters namely Traverse rate $(\mathrm{mm} / \mathrm{min})$, Abrasive flow rate (grams/min) and Standoff distance $(\mathrm{mm})$ to analyze its effect on MRR ( $\mathrm{grams} / \mathrm{min}$ ) and Surface Roughness $(\mu \mathrm{m})$ on AWJM for Inconel $800 \mathrm{H}$. The selected process parameters were evaluated in three levels as shown in Table 1.

Table 2. Constant Machining Parameters

\begin{tabular}{|c|c|}
\hline Abrasive type & Garnet \\
\hline Abrasive Size & 80 Mesh \\
\hline Water pressure & $3800 \mathrm{bar}$ \\
\hline Orifice diameter & $0.35 \mathrm{~mm}$ \\
\hline Nozzle diameter & $1.1 \mathrm{~mm}$ \\
\hline Work piece thickness & $6 \mathrm{~mm}$ \\
\hline
\end{tabular}

The following machining parameters as shown in Table 2 were kept constant.

Table 3. L9 Orthogonal array with machining parameters

\begin{tabular}{|c|c|c|c|}
\hline $\begin{array}{c}\mathrm{S} \\
\text { No }\end{array}$ & $\begin{array}{c}\text { Traverse speed } \\
(\mathrm{mm} / \mathrm{min}) \\
(\mathrm{S})\end{array}$ & $\begin{array}{c}\text { Abrasive flow } \\
\text { rate }(\text { grams/min }) \\
(\mathrm{R})\end{array}$ & $\begin{array}{c}\text { Standoff } \\
\text { distanc }(\mathrm{mm}) \\
(\mathrm{H})\end{array}$ \\
\hline 1 & 160 & 500 & 2 \\
\hline 2 & 160 & 600 & 3 \\
\hline 3 & 160 & 700 & 4 \\
\hline 4 & 200 & 500 & 3 \\
\hline 5 & 200 & 600 & 4 \\
\hline 6 & 200 & 700 & 2 \\
\hline 7 & 225 & 500 & 4 \\
\hline 8 & 225 & 600 & 2 \\
\hline 9 & 225 & 700 & 3 \\
\hline
\end{tabular}

For each experiment, the machining parameters were set to the pre-defined levels according to the orthogonal array as shown in Table 3.

\section{Results and Discussions}

Surface roughness is one of the most important quality control parameter for assessing a production process. In the present investigation it was found that the machined surface is smoother near the jet entrance and gradually becomes rougher towards the jet exit. This is due to the fact that as the particles moves down they lose their kinetic energy and their cutting ability deteriorates. By analyzing the experimental data of the selected material, it has been found that the optimum selection of the three basic parameters, i.e., abrasive mass flow rate, nozzle traverse speed and nozzle standoff distance are very important on controlling the process outputs such as material removable rate, surface roughness. The effect of each of these parameters was studied while keeping the other parameters as constants as shown Table 2.

Table 4 shows the experimental observations on MRR and SR at the selected machining parameters depicted in Table 3.As can be seen from Table 4, MRR was maximum when all the selected parameters were set at their maximum. However, the surface roughness showed moderate value of $2.67 \mu \mathrm{m}$ against lowest value of $2.28 \mu \mathrm{m}$. If viewed from the point of lowest value of surface roughness MRR showed moderate value.

Table 4. Experimental Observations

\begin{tabular}{|c|c|c|c|c|c|}
\hline $\begin{array}{c}\mathrm{S} \\
\text { No }\end{array}$ & $\begin{array}{c}\text { Traverse } \\
\text { speed } \\
(\mathrm{mm} / \mathrm{min}) \\
(\mathrm{S})\end{array}$ & $\begin{array}{c}\text { Abrasive } \\
\text { flow rate } \\
(\text { grams/min }) \\
(\mathrm{R})\end{array}$ & $\begin{array}{c}\text { Standoff } \\
\text { distance } \\
(\mathrm{mm}) \\
(\mathrm{H})\end{array}$ & $\begin{array}{c}\text { MRR } \\
(\mathrm{grams} / \mathrm{min})\end{array}$ & $\begin{array}{c}\mathrm{SR} \\
(\mu \mathrm{m})\end{array}$ \\
\hline 1 & 160 & 500 & 2 & 4.54 & 2.80 \\
\hline 2 & 160 & 600 & 3 & 4.84 & 2.40 \\
\hline 3 & 160 & 700 & 4 & 5.04 & 2.28 \\
\hline 4 & 200 & 500 & 3 & 4.59 & 2.70 \\
\hline 5 & 200 & 600 & 4 & 4.96 & 2.48 \\
\hline 6 & 200 & 700 & 2 & 5.06 & 2.60 \\
\hline 7 & 225 & 500 & 4 & 5.28 & 2.72 \\
\hline 8 & 225 & 600 & 2 & 5.27 & 3.00 \\
\hline 9 & 225 & 700 & 3 & 5.49 & 2.67 \\
\hline
\end{tabular}

Table $5 \& 6$ respectively shows results of ANOVA and F-tests conducted for MRR and SR. Nozzle Transverse speed showed better influence on the MRR than other parameters. On the other hand, standoff distance was found to be influencing surface roughness more than other machining parameters. Table 7 shows signal to noise ratio values for MRR and SR. 
Table 5. Analysis of Variance And F-Test for Mrr

\begin{tabular}{|c|c|c|c|c|c|c|c|}
\hline Parameter (Y) & Sum square & DOF & Variance & F ratio & F-tabulated & Percent & Rank \\
\hline S & 1.55 & 2 & 0.77 & 15.752 & 5.12 & $63 \%$ & 1 \\
\hline $\mathrm{R}$ & 0.75 & 2 & 0.37 & 7.598 & 5.12 & $30 \%$ & 2 \\
\hline $\mathrm{H}$ & 0.12 & 2 & 0.06 & 1.202 & 5.12 & $5 \%$ & 3 \\
\hline Error & 0.05 & 6 & 0.01 & & & & \\
\hline Total & 2.46 & 1 & & & & & \\
\hline
\end{tabular}

Table 6. Analysis of Variance and F-Test for $\mathrm{Sr}$

\begin{tabular}{|c|c|c|c|c|c|c|c|}
\hline Parameter (Y) & Sum square & DOF & Variance & F ratio & F-tabulated & Percent & Rank \\
\hline S & 1.56 & 2 & 0.78 & 19.57 & 5.12 & $37 \%$ & 2 \\
\hline R & 0.65 & 2 & 0.32 & 8.09 & 5.12 & $15 \%$ & 3 \\
\hline H & 1.995 & 2 & 0.998 & 25.02 & 5.12 & $47 \%$ & 1 \\
\hline Error & 0.04 & 6 & 0.01 & & & & \\
\hline Total & 4.24 & 1 & & & & & \\
\hline
\end{tabular}

Table 7. Signal to Noise Ratios of MRR and SR

\begin{tabular}{|c|c|c|c|c|c|c|c|}
\hline S No & $\begin{array}{c}\text { Traverse speed } \\
(\mathrm{mm} / \mathrm{min})(\mathrm{S})\end{array}$ & $\begin{array}{c}\text { Abrasive flow } \\
\text { rate }(\text { grams/min) } \\
(\mathrm{R})\end{array}$ & $\begin{array}{c}\text { Standoff } \\
\text { distance }(\mathrm{mm}) \\
(\mathrm{H})\end{array}$ & $\begin{array}{c}\text { MRR } \\
\text { (grams/min) }\end{array}$ & SR $(\mu \mathrm{m})$ & $\begin{array}{c}\text { S/N ratio } \\
\text { for MRR }\end{array}$ & $\begin{array}{c}\text { S/N ratio } \\
\text { for SR }\end{array}$ \\
\hline 1 & 160 & 500 & 2 & 4.54 & 2.80 & 13.14 & -8.94 \\
\hline 2 & 160 & 600 & 3 & 4.84 & 2.40 & 13.70 & -7.60 \\
\hline 3 & 160 & 700 & 4 & 5.04 & 2.28 & 14.05 & -7.16 \\
\hline 4 & 200 & 500 & 3 & 4.59 & 2.70 & 13.23 & -8.63 \\
\hline 5 & 200 & 600 & 4 & 4.96 & 2.48 & 13.92 & -7.89 \\
\hline 6 & 200 & 700 & 2 & 5.06 & 2.60 & 14.09 & -8.63 \\
\hline 7 & 225 & 500 & 4 & 5.28 & 2.72 & 14.46 & -8.69 \\
\hline 8 & 225 & 600 & 2 & 5.27 & 3.00 & 14.44 & -9.54 \\
\hline 9 & 225 & 700 & 3 & 5.49 & 2.67 & 14.80 & -8.53 \\
\hline
\end{tabular}

\subsection{Material Removal Rate (MRR)}

Main effects of each of the machining parameters on MRR are shown in figure 1 and response table 8 . According to the response table 8 and figure 1 the MRR increases with three major parameter transverse speed $(S)$, abrasive flow rate $(R)$, and standoff distance ( H ). MRR is maximum in the case of Traverse Speed(S) at level $3(225 \mathrm{~mm} / \mathrm{min})$, in the case of Abrasive flow Rate (R) at level 3 (700 grams $/ \mathrm{min})$, in the case of Standoff distance (H) MRR will be maximum at level $3(4 \mathrm{~mm})$. So the optimal parameter setting for the MRR found S3R3H3

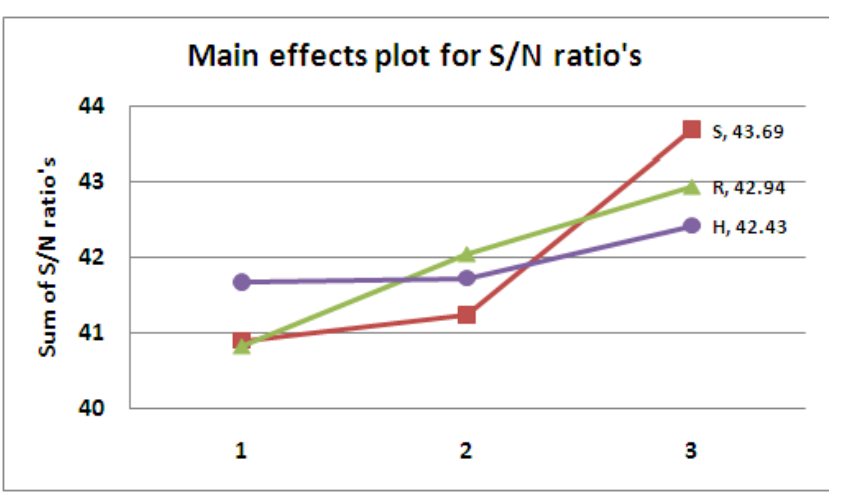

Figure 1. $\mathrm{S} / \mathrm{N}$ ratio of MRR ( Signal ration larger is the better ) 
Table 8. Response of MRR to Signal to Noise Ratios in each of the machining parameter

\begin{tabular}{|c|c|c|c|}
\hline Level & $\mathrm{S}$ & $\mathrm{R}$ & $\mathrm{H}$ \\
\hline 1 & 40.90 & 40.83 & 41.67 \\
\hline 2 & 41.24 & 42.06 & 41.73 \\
\hline 3 & 43.69 & 42.94 & 42.43 \\
\hline$\Delta$ & 2.79 & 2.11 & 0.76 \\
\hline Rank & 1 & 2 & 3 \\
\hline
\end{tabular}

\subsection{Surface Roughness (SR)}

Figure 2 and response table 9 evaluates the main effects of each of the machining parameters on surface roughness. According to the data shown Table 9 and also depicted in figure 2 the surface Roughness decreases with three major parameter transverse speed (S), abrasive flow rate ( R ), and standoff distance ( $\mathrm{H}$ ). Surface roughness ( SR ) will be minimum in the case of Traverse Speed (S) at level 3 (225 $\mathrm{mm} / \mathrm{min})$, in the case of Abrasive flow Rate(R) at level 1 (500 grams / $\mathrm{min}$ ), in the case of Standoff distance $(\mathrm{H})$ at level $1(2 \mathrm{~mm})$. So the optimal parameter setting for the SR found S3R1H1.

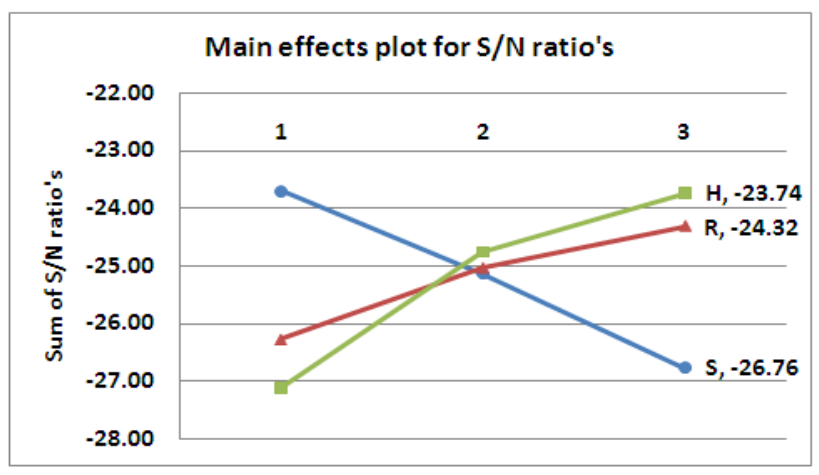

Figure 2. $\mathrm{S} / \mathrm{N}$ ratio of $\mathrm{SR}$ ( $\mathrm{S} / \mathrm{N}$ ratio smaller is better )

Table 9. Response of SR to Signal to Noise Ratios in each of the machining parameter

\begin{tabular}{|c|c|c|c|}
\hline Level & $\mathrm{S}$ & $\mathrm{R}$ & $\mathrm{H}$ \\
\hline 1 & -23.71 & -26.26 & -27.11 \\
\hline 2 & -25.14 & -25.04 & -24.76 \\
\hline 3 & -26.76 & -24.32 & -23.74 \\
\hline$\Delta$ & 3.06 & 1.95 & 3.37 \\
\hline Rank & 2 & 3 & 1 \\
\hline
\end{tabular}

The confirmation experiments were conducted using the optimum combination of the machining parameters obtain from Taguchi analysis. These confirmation experiments were used to predict and verify the improvement in the quality characteristics for machining of Inconel $800 \mathrm{H}$. For MRR and SR predicted process combination is S3R3H3 and S3R1H1 respectively. The optimal response values are MRR
$5.87 \mathrm{grams} / \mathrm{min}$ and SR $2.8 \mu \mathrm{m}$.

\section{Conclusions}

This paper presents optimization of the process parameters on abrasive water jet machining for Inconel $800 \mathrm{H}$ material by taking Material removable rate ( MRR ) and surface roughness ( SR ) as responses. The following conclusions can be drawn for effective machining of Inconel alloy $800 \mathrm{H}$ by AWJM process as follows:

- Traverse Speed (S) plays a major role on influencing material removable rate (MRR)by $60 \%$ as observed in ANOVA F test. Then the major contribution on MRR is abrasive Flow Rate which is about 30\%. We also observed that Standoff distance is sub significant in influencing MRR.

- The confirmation experiments were conducted using the optimum combination of the machining parameters obtained from Taguchi analysis. The recommended parametric combination for optimum material removal rate is $\mathrm{S} 3 \mathrm{R} 3 \mathrm{H} 3$ and the optimum response value of MRR is 5.87 grams $/ \mathrm{min}$

- In case of surface Roughness Standoff distance and Transverse speed plays major significance of about $47 \%$ and $37 \%$ respectively. Abrasive flow rate is having sub significance influence on SR.

- The confirmation experiments were conducted on Surface roughness with S3R1H1 levels as obtained from Taguchi analysis. The optimal response values for Surface roughness are $2.8 \mu \mathrm{m}$.

- These test results provides us a greater detail in selecting significant parameters on output parameters such as MRR, SR while machining Inconel $800 \mathrm{H}$ material on abrasive water jet machining.

\section{REFERENCES}

[1] LeeladharNagdeve, VedanshChaturvedi, JyotiVimal, (2012) Parametric optimization of abrasive waterjet machining using taguchi methodology; International Journal of Research in Engineering \& Applied Sciences, Volume 2, Issue 6.ISSN: 2249-3905, pages 23 to 32 .

[2] M. Chithiraiponselvan, N. Mohanasundara raju, H. K. Sachidananda; (2012 ) effects of process parameters on surface roughness in abrasive water jet cutting of aluminum, Frontiers of Mechanical Engineering, Volume 7, Issue 4, pp.439-444.

[3] LeeladharNagdeve, VedanshChaturvedi, JyotiVimal, (2012) Implementation of Taguchi approach for optimization of abrasive water jet machining process parameters, International Journal of Instrumentation, Control and Automation (IJICA) ISSN: 2231-1890, Vol-1 Iss-3,4. Pages 9 to 13 . 
[4] M. Chithiraiponselvan and Dr. N. Mohanasundara raju, (2012) Analysis of surface roughness in abrasive waterjet cutting of cast iron; International journal of science, environment and technology, vol. 1, no 3, pages 174 to 182 .

[5] M. A. Azmir1, A.K. Ahsan, A. Rahmah, (2007) Investigation on abrasive water jet machining of kevlar reinforced phenolic composite using Taguchi approach, Proceedings of the
International Conference on Mechanical Engineering (ICME2007) . Dhaka, Bangladesh

[6] Vaibhav.j.limbachiya, Prof Dhaval.M.Patel, (2011) An Investigation of Different Material on Abrasive Water jet Machine; International Journal of Engineering Science and Technology (IJEST)ISSN : 0975-5462 Vol. 3 No. 7 Pages 5940 to 5945 . 